\title{
REVIEW
}

\section{Mechanisms underlying proglucagon gene expression}

\author{
Tianru Jin ${ }^{1,2}$ \\ ${ }^{1}$ Departments of Medicine, Physiology, and Laboratory Medicine and Pathobiology, University of Toronto, Toronto, Ontario, Canada \\ ${ }^{2}$ Division of Cell and Molecular Biology, Toronto General Research Institute, University Health Network, Room 10-354, 10th Floor, Toronto Medical Discovery \\ Tower, 101 College Street Toronto, Ontario, M5G 1L7, Canada \\ (Correspondence should be addressed to T Jin; Email: tianru.jin@utoronto.ca)
}

\begin{abstract}
The proglucagon gene $(\mathrm{gcg})$ encodes a number of peptide hormones that are of cell-type specifically expressed in the pancreatic islets, the distal ileum and the large intestine, as well as certain brain neuronal cells. These hormones are important in controlling blood glucose homeostasis, intestinal cell proliferation, and satiety. More importantly, the major hormone generated in the pancreas (i.e. glucagon) exerts opposite effects to the ones that are produced in the intestines (i.e. glucagon-like peptide-1 (GLP-1) and GLP-2). To understand the mechanisms underlying cell-type-specific gcg expression may lead to the identification of novel drug targets to control endogenous hormone production for therapeutic purposes. Extensive in vitro examinations have shown that more than a half dozen of homeodomain (HD) proteins are able to interact with the gcg gene promoter and
\end{abstract}

activate its expression. In vivo 'knock-out' mouse studies, however, cannot demonstrate the role of some of them (i.e. Cdx-2, Brn-4, and Nkx6.2) in the development of pancreatic islet $\boldsymbol{\alpha}$-cells, suggesting that these HD proteins may exert some redundant functions in the genesis of gcg-producing cells. Investigations have also revealed that gcg expression is controlled by both protein kinase A and Epac signaling pathways in response to cAMP elevation, and cell-type specifically controlled by insulin and the effectors of the Wnt signaling pathway. This review summarizes our current understanding on the mechanisms underlying gcg transcription and presented my interpretations on how the interactions between different signaling networks regulate gcg expression. Journal of Endocrinology (2008) 198, 17-28

\section{Introduction}

The gene that encodes glucagon, namely the proglucagon gene $(\mathrm{gcg})$, was isolated from rodents and humans in the early 1980s (Bell et al. 1983a,b, Lopez et al. 1983, Heinrich et al. 1984, Irwin 2001). The analysis of gcg cDNAs from these species further revealed that it encodes not only glucagon but also two glucagon-like peptide hormones, namely glucagonlike peptide-1 (GLP-1) and GLP-2 (Lund et al. 1982).

Glucagon is produced and released from the pancreatic $\alpha$-cells. The major physiological function of glucagon is the stimulation of hepatic glucose release, and it has been utilized in treating patients with hypoglycemia and other disorders (Sinclair \& Drucker 2005). Glucagon exerts its biological functions through binding to its receptor, which is expressed in the brain, pancreas, small and large intestines, kidney, and more importantly liver and adipose tissues (Jelinek et al. 1993, Campos et al. 1994, Burcelin et al. 1996, Christophe 1996).

GLP-1 and GLP-2 are generated and released from the enteroendocrine $\mathrm{L}$ cells in the distal ileum, large intestine, and certain neuronal cells of the brain (Brubaker \& Drucker 2004,
Kieffer 2004, Drucker 2006). GLP-1 stimulates postprandial insulin secretion and activates the transcription and biosynthesis of insulin (Brubaker \& Drucker 2004, Kieffer 2004, Drucker 2006, Doyle \& Egan 2007). In addition, GLP-1 may stimulate proliferation and neogenesis of pancreatic $\beta$-cells (Brubaker \& Drucker 2004, List \& Habener 2004, Bonner-Weir \& Weir 2005, Drucker 2006, Wideman et al. 2006, 2007, Doyle \& Egan 2007). The long-acting GLP-1 receptor (GLP-1R) agonist, exendin-4, has been utilized in the differentiation or trans-differentiation of insulin-producing cells from both somatic and embryonic stem cells (Abraham et al. 2002, Brubaker \& Drucker 2004, Kieffer 2004, List \& Habener 2004, Bonner-Weir \& Weir 2005, Doyle \& Egan 2007). Other physiological functions of GLP-1 include the inhibition of glucagon release and gastric emptying and the enhancement of peripheral insulin sensitivity (Drucker 2002). In addition, GLP-1 administration in the brain inhibits food intake (Turton et al. 1996, Meeran et al. 1999). Based on these findings, exenatide (commercially known as Byetta) has been developed and approved clinically for treating type II diabetes mellitus (T2D) and related 
disorders (Holst 2006). GLP-2 is co-expressed with GLP-1 in the intestinal L cells and the brain. The function of GLP-2 was first identified by Drucker et al. (1996) as a growth factor of small intestines. It stimulates the proliferation of small intestinal crypt cells and inhibits cell apoptosis (Drucker 2001, Jeppesen 2003). This property makes GLP-2 a potential therapeutic agent in the treatment of intestinal injury (Jeppesen 2003). Furthermore, another intestinal product, oxyntomodulin, may prove useful as an anti-obesity drug (Murphy et al. 2006).

Extensive examinations in the exploration of mechanisms underlying gcg transcription have led to the identification of a minimum promoter region (G1) and four enhancer elements (G2-G5) in the gcg gene promoter (Philippe et al. 1987a, Herzig et al. 2000; Fig. 1). In addition, gcg transcription can be regulated by cAMP, amino acids, and a number of homeodomain (HD) protein transcription factors (Knepel et al. 1990, Drucker et al. 1994, Jin \& Drucker 1996, Gevrey et al. 2004). More recently, intestinal but not pancreatic gcg expression was shown to be regulated by the effectors of the Wnt signaling pathway ( $\mathrm{Ni}$ et al. 2003, Yi et al. 2005). Furthermore, insulin at pathological concentrations was shown to stimulate intestinal gcg mRNA and GLP-1 production (Yi et al. 2008), in contrast to its known inhibitory effect on gcg expression in pancreatic $\boldsymbol{\alpha}$-cells (Philippe 1989, 1991). In this review, a summary of our current knowledge on the transcriptional regulation of gcg expression, focusing on the role of HD protein transcription factors, cAMP signaling, and the Wnt signaling pathway is presented. Mechanisms controlling secretion and function of glucagon

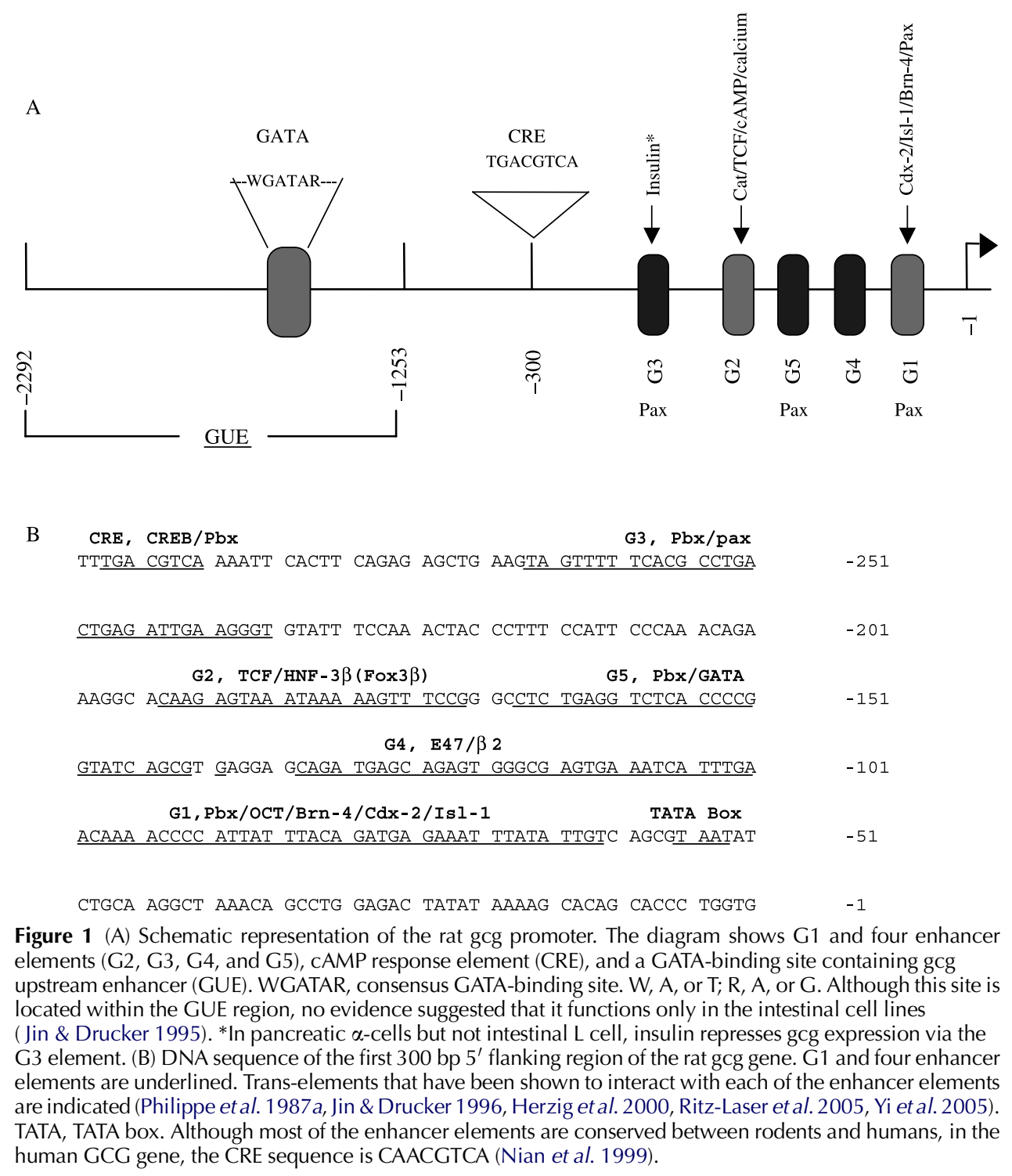


and GLP-1 have been extensively reviewed elsewhere (Brubaker \& Drucker 2004, Holz, 2004, Kieffer, 2004, Bonner-Weir \& Weir 2005, Drucker 2006, Holst 2006, Doyle \& Egan 2007).

\section{HD proteins and proglucagon gene expression}

Nearly a dozen HD proteins were shown to be expressed in pancreatic $\alpha$ and/or intestinal endocrine L cells, including the LIM protein Isl-1 (Dong et al. 1991, Wang \& Drucker 1995), a number of paired HD proteins (Hussain \& Habener 1999, Ritz-Laser et al. 1999, 2000, 2002, Zaiko et al. 2004), caudal HD protein Cdx-2 (German et al. 1992, Jin \& Drucker 1996, Hussain \& Habener 1999, Ritz-Laser et al. 1999), POU HD protein Brn-4 and Oct-1 (Wang et al. 2006), and members of the TALE (Herzig et al. 2000, Liu et al. 2006), and Nkx families (Sander et al. 2000, Pedersen et al. 2005, Nelson et al. 2007). Although most of them were shown to stimulate gcg promoter expression in the in vitro examinations, only a few of them were demonstrated to be essential for the development of pancreatic islets and $\boldsymbol{\alpha}$-cell genesis in the 'knock-out' mouse studies.

\section{Isl-1}

Isl-1 is expressed in all hormone-producing islet cells in adult mice (Dong et al. 1991, Thor et al. 1991, Ericson et al. 1992). In vitro studies have shown that Isl-1 regulates transcription of the insulin, gcg, and somatostatin genes (Karlsson et al. 1990, Vallejo et al. 1992, Wang \& Drucker 1995, Peng et al. 2005). Targeted disruption of Isl-1 in mice results in an early arrest of embryonic development, with the failure of the development of the dorsal pancreatic mesenchymal and the complete absence of pancreatic endocrine cells (Pfaff et al. 1996). Wang \& Drucker (1995) demonstrated that the proximal rat gcg promoter interacted with an amino-terminally truncated Trp-E-Isl-1 fusion protein that lacked the LIM domains, or a full-length in vitro translated Isl-1 that contained intact LIM domains. Furthermore, they observed Isl-1-mediated activation of gcg promoter in the pancreatic $\boldsymbol{\alpha}$-cell line InR1-G9. This study not only indicates that Isl-1 is a transcriptional activator of gcg but also suggests that LIM domains are not necessarily involved in the interaction with the target promoters by the LIM HD proteins (Wang \& Drucker 1995).

\section{Pax proteins}

Ritz-Laser et al. (2000) found that Pax-2 binds to motifs within the G3 and G1 enhancer elements of the gcg prompter and activates its transcription. Flock \& Drucker (2002) found that although in cultured cell lines, Pax- 2 did bind to the gcg promoter and activated its transcription, Pax-2 mRNA transcripts were not detected by RT-PCR in RNA isolated from adult rat pancreas, rat islets, embryonic d19 or adult murine pancreas, and gastrointestinal tract. Furthermore, embryonic d19 or neonatal d1 Pax-2 (1Neu) mice exhibited normal islet $\boldsymbol{\alpha}$-cells and intestinal endocrine $\mathrm{L}$ cells and no decrease in pancreatic or intestinal glucagon gene expression (Flock \& Drucker 2002). In the same Pax-2 (1Neu) mutant mice, Ritz-Laser et al. found a two- to threefold increase in the average pancreas volume (Zaiko et al. 2004). Because this increase was not accompanied by significant modification in the insulin or glucagon content in the pancreas, Ritz-Laser et al. suggested that the content of these hormones per cell is decreased (Zaiko et al. 2004).

Pax-6 is an important factor in islet cell development (Habener et al. 2005). It is expressed early in the epithelium of both dorsal and ventral pancreatic buds of the developing pancreas. The Sey ${ }^{-1-}$ mice carry a spontaneous mutation of the Pax-6 gene (Stoykova et al. 1996). These mice show abnormal organization of the islets, with decreased numbers of $\alpha, \beta, \delta$, and PP cells, associated with substantially reduced glucagon and insulin production (Sander et al. 1997). Pax-6 was shown to synergize with $\mathrm{Cdx}-2$ in stimulating gcg promoter expression (Ritz-Laser et al. 1999). Pax6 $6^{-1-}$ mice die shortly after birth and fail to form pancreatic islets (St-Onge et al. 1997). Trinh et al. (2003) demonstrated that Pax-6 was able to stimulate gcg expression in intestinal endocrine L cells, following an adenovirus-mediated overexpression procedure.

\section{$C d x-2$}

Cdx-2 is a caudal-like HD protein in mammals. Hamster Cdx-2 ( $=\mathrm{Cdx}-3$ or $\mathrm{Cdx}-2 / 3)$ was isolated by German et al. (1992) from the pancreatic $\beta$-cell line HIT. Cdx-2 expression was also detected in the pancreatic $\boldsymbol{\alpha}$-cell line InR1-G9, intestinal GLUTag and STC-1 cell lines, and in the mouse pancreas (Jin \& Drucker 1996). Cdx-2 was shown to bind to two AT-rich motifs within the G1 enhancer element of the gcg promoter (Fig. 2). Cdx-2 co-transfection substantially stimulated the expression of gcg promoter and the stimulation was abolished if the Cdx-2-binding sites were mutated ( Jin \& Drucker 1996). Furthermore, Cdx-2 over-expression in the pancreatic InR1-G9 cell line led to an increased endogenous gcg mRNA expression (Jin et al. 1997). Laser et al. (1996) however, demonstrated that the InR1-G9 cell line expressed two alternatively spliced isoforms of $\mathrm{Cdx}-2$, and the longer one functioned as the major stimulator of gcg transcription. Furthermore, Cdx-2, Pax-6, and the nuclear co-activator P300 could exert synergistically a stimulatory effect on gcg promoter expression (Hussain \& Habener 1999, Ritz-Laser et al. 1999).

$C d x-2^{-/-}$mice die during $3 \cdot 5-5 \cdot 5 \mathrm{dpc}$, due to a fundamental role of $\mathrm{Cdx}-2$ in embryo implantation (Chawengsaksophak et al. 1997). $C d x-2^{+/-}$mice were shown to develop multiple malfunctions, including stunted growth, shortened tails, and abnormalities in their vertebral development. More importantly, $90 \%$ of the $C d x-2^{+/-}$mice were shown to develop colorectal polyps by 3 months after birth, indicating that $\mathrm{Cdx}-2$ is a potential tumor suppressor (Chawengsaksophak et al. 1997). Interestingly, pancreatic 

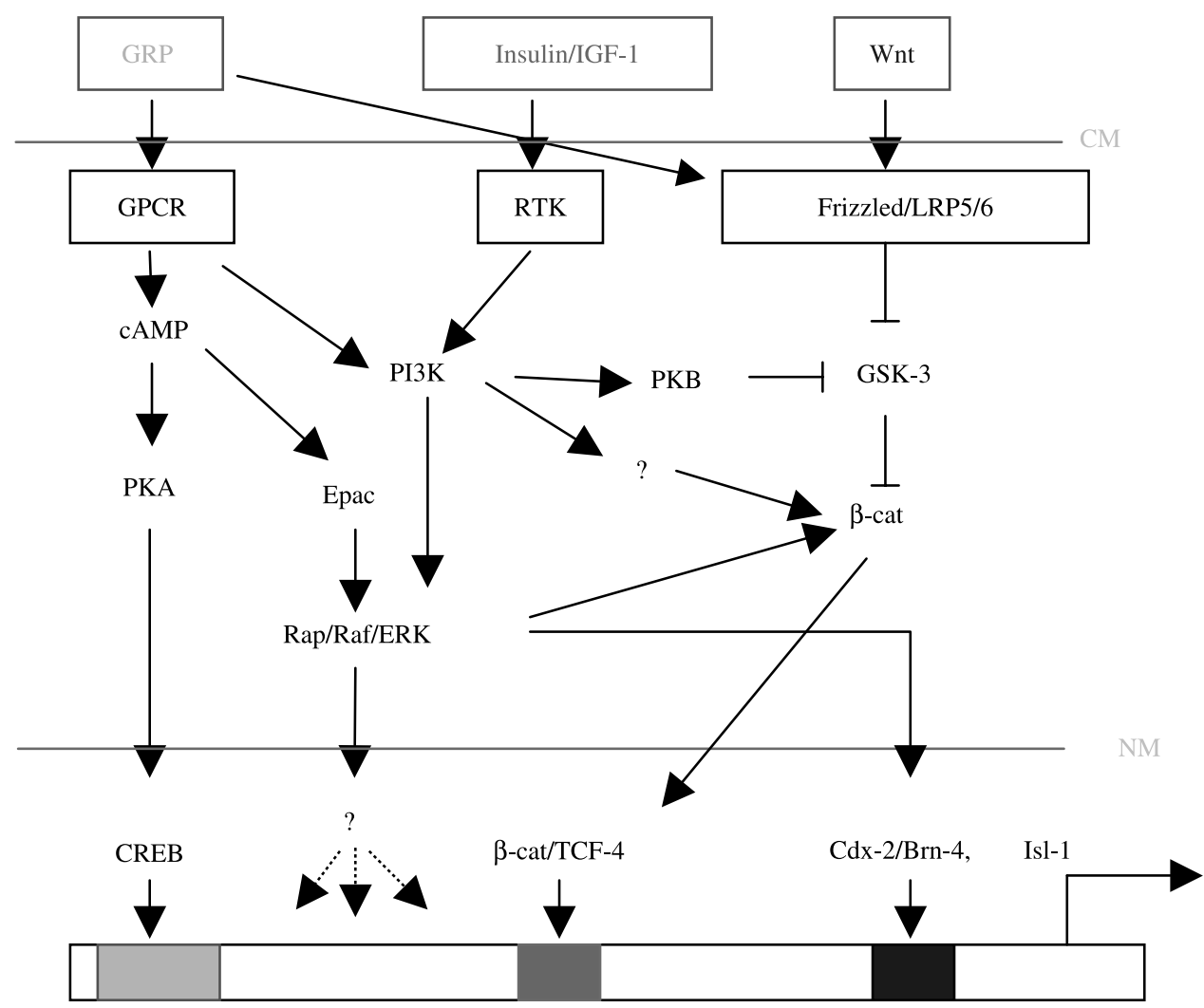

CRE/CRE like

G2

G1

Figure 2 Summary of our current understanding on the mechanisms underlying gcg expression. A neurotransmitter or growth factor, such as gastrin-releasing peptide (GRP; Lu et al. 1996), may exert its stimulatory effect via a G-protein-coupled receptor (GPCR). Insulin and IGF-1, on the other hand, activate a correspondent receptor tyrosine kinase (RTK). Wnt ligands usually bind to their receptors, frizzleds, and co-receptor LRP5/6. The elevation of CAMP in response to GPCR activation may up-regulate gcg transcription via 1) PKA-CREB, with the CRE and CRE-like elements as the correspondent cis-elements (Knepel et al. 1990, Jin \& Drucker 1996, Gevrey et al. 2004), and 2) Epac-Rap-Raf-ERK signaling pathway, via unknown cis-elements, shown as dotted arrows. ERK is also involved in CAMP-stimulated expression of $\mathrm{Cdx}-2$, a known transactivator of gcg, via the G1 element (Chen et al. 2005). Furthermore, ERK could be involved in $\beta$-cat phosphorylation and nuclear translocation (Ding et al. 2005). Insulin and IGF-1 are able to stimulate $\beta$-cat nuclear translocation and binding of cat/TCF-4 to the G2 element, a process involving PI3K and a yet to be determined signaling pathway (Yi et al. 2008). Finally, hormones and growth factors that use GPCR as their receptors may crosstalk with the Wnt pathway via two potential mechanisms. First, a GPCR may stabilize $\beta$-cat via PI3K activation, presented recently by Liu \& Habener (2008) in studying the function of GLP-1. Second, since frizzleds share structure homology with GPCRs, hormones and growth factors that use GPCR as their receptors may trigger the crosstalk with the Wnt signaling pathway at the receptor level (Malbon 2004).

development in the $C d x-2^{+/-}$mice appeared normal. In the pancreatic InR1-G9 cell line, Cdx-2 was shown to bind to two AT-rich motifs within the proximal promoter region of Cdx-2 and stimulate its own transcription (Xu et al. 1999). Binding to a motif downstream of the transcription start site appeared to be involved in stimulating promoter expression, while binding to the TATA box appeared to attenuate the activation. We have proposed that one functional $\mathrm{Cdx}-2$ allele is sufficient for maintaining its normal function in pancreatic and intestinal gcg-producing endocrine cells due to the existence of such an efficient auto-regulatory mechanism (Xu et al. 1999).
Brn-4

Brn-4 is highly expressed in neural stem cells and regulates stem cell-specific gene expression (Heller et al. 2004). Brn-4 is also expressed in pancreatic $\alpha$-cells but not $\beta$-cells, and its capability in activating gcg expression was first demonstrated by Hussain et al. (1997). Brn-4 expression starts at e10 in the pancreas, just before the expression of Pax-6. At time point of e19, no Brn-4 co-localization was observed with insulin or somatostatin, suggesting that Brn-4 is a pancreatic $\alpha$-cellspecific transcription factor. Wang et al. (2001) have shown 
that induced Brn-4 expression in the INS-1 $\beta$-cell line initiated detectable expression of glucagon without affecting $\beta$-cell-specific gene expression. Later, Hussain et al. (2002) reported that mis-expression of Brn-4 by the $\beta$-cell-specific $\mathrm{Pdx}-1$ gene promoter resulted in ectopic expression of the gcg gene in insulin-expressing pancreatic $\beta$-cells in mice. These observations strongly suggest the role of this 'master' control gene in directing the development of $\alpha$-cell lineage. Surprisingly, in $\mathrm{Brn}-4^{-1-}$ mice, pancreatic bud formation, gcg-expressing cell numbers, and related physiological measurements all appear normal (Heller et al. 2004). Whether Brn-4 is not important for pancreatic $\alpha$-cell development or the absence of abnormality in pancreatic $\alpha$-cells in $B r n-4^{-/-}$ mice is due to the existence of redundant factors remain unresolved.

Both Cdx-2 and Brn-4 interact with motifs of the gcg promoter G1 element (Fig. 1). Their binding sites are separated by only $8 \mathrm{bp}$. Ectopic expression of either Cdx-2 or Brn-4 in the insulin-producing In111 cell line was shown to result in gcg mRNA expression (Wang et al. 2006). Brn-4 synergized with $\mathrm{Cdx}-2$ in activating gcg promoter, and its activation domain was not required for this synergistic function (Wang et al. 2006). These observations further suggest that HD proteins in different families could have both synergistic and redundant effects on their target gene expression (Wang et al. 2006).

\section{Pbx proteins}

$\mathrm{Pbx}$ proteins are able to associate with most members of the Hox HD protein family and certain Hox-related HD proteins, including Cdx-2 (Liu et al. 2006). This association may enhance the binding selectivity and affinity of Hox and Hox-related proteins to their target promoters. It has been suggested that a penta-peptide motif, localized in many Hox and Hox-related HD proteins, is involved in the interaction with $\mathrm{Pbx}$ proteins (Berthelsen et al. 1999).

The expression of $\mathrm{Pbx} 1$ in the embryonic pancreas starts at $\mathrm{e} 10 \cdot 5$. After that $\mathrm{Pbx}-1$ is expressed in a gradient manner with a high level of expression in pancreatic mesenchyme and vascular endothelium, a modest level in central ductal epithelia, and low expression level in more peripheral exocrine pancreatic epithelium cells. In adult mice, Pbx-1 is detectable in all four islet hormone-producing cells, acinar cells, and at the highest level in the ductal cells. The expression pattern of $\mathrm{Pbx}-1$ suggested that it may play a role in pancreatic development and in maintaining normal pancreatic functions (Kim et al. 2002). Pbx-1 $1^{-/-}$mice die at e15-e16 with hypoplasia or aplasia of many organs, including the pancreas where marked defects of exocrine and endocrine cells were observed (Kim et al. 2002). At e10.5, $P b x-1^{-1-}$ mice showed less compact and disordered dorsal pancreatic mesenchyme. At e13.5-e14, dorsal and ventral pancreatic hypoplasia were found. Further abnormalities in both dorsal and ventral pancreas were observed at e15. Detailed analysis of these embryos revealed cell morphological defects and suggested that $\mathrm{Pbx}-1$ was required for embryonic pancreas cell growth and survival. At e14.5, $\sim 35-40 \%$ reduction in pancreatic cell proliferation in the $\mathrm{Pbx}-1^{-/-}$embryo was recorded. Isl-1 and another transcription factor, Atoh5, which are important for pancreatic cell differentiation, were found to be repressed in the $P b \times-1^{-/-}$mice, followed by impaired pancreatic cell differentiation. Interestingly, $P b x-1^{+/-}$mice also showed islet malformation and hyperinsulinemia (Kim et al. 2002). These observations indicate an essential role for Pbx- 1 in maintaining normal pancreatic development and physiology.

Since the penta-peptide motif involved in the interaction with $\mathrm{Pbx}$ proteins is also present in $\mathrm{Cdx}-2$ and other caudal $\mathrm{HD}$ proteins, Liu et al. (2006) have detected the interaction between $\mathrm{Cdx}-2$ and $\mathrm{Pbx}-1$ and examined whether $\mathrm{Pbx}-1$ functions as a co-factor of $\mathrm{Cdx}-2$ in regulating gcg expression. $\mathrm{Pbx}-1$ co-transfection was shown to enhance the activation of gcg promoter by $\mathrm{Cdx}-2$ and mutating the penta-peptide motif attenuated the stimulatory effect of Cdx-2 (Liu et al. 2006).

\section{Nkx family}

Nkx.2.2 is expressed in $\alpha, \beta$ and PP cells, but not in the $\delta$ cells. Sussel et al. (1998) demonstrated that $N k \times 2.2^{-1-}$ mice develop severe hyperglycemia and die shortly after birth. The mutant embryos lack insulin-producing cell and have fewer glucagon- or PP-producing cells. Sander et al. (2000) found that disruption of $\mathrm{Nkx} 6.1$ leads to the loss of $\beta$-cell precursor and the lack of $\beta$-cell neogenesis during the secondary transition period (e13 and after). Because Nkx6.1/Nkx2.2 double mutant mice showed identical phenotypes with that of the Nkx2.2 $2^{-/-}$mice, Sander et al. (2000) suggested that Nkx6.1 is downstream of Nkx2.2. More recently, Schisler et al. (2005) reported that Nkx6.1 binds to the gcg promoter and represses endogenous gcg mRNA expression. The Nkx6.1 paralog, Nkx6.2, is also expressed in pancreatic islet cells. Although $N k x 6.2^{-/-}$mice were shown to be fertile and lack a detectable defect (Cai et al. 2001), Henseleit et al. (2005) demonstrated that Nkx6.2 could exert redundant functions to Nkx6.1 in the development of both pancreatic $\alpha$ and $\beta$-cells. Nelson et al. (2007) assessed the capability for rescuing insulin-producing $\beta$-cells in the $N k \times 6.1^{-/-}$mice with different Nkx6-expressing transgenes. The formation and maturation of $\beta$-cells was restored when Nkx6.1 expression was driven by the $\mathrm{Pdx}-1$ gene promoter, but not by the Neurog3 (Ngn3) promoter. More interestingly, Pdx-1driven Nkx6.2 also rescued insulin-producing $\beta$-cells in the Nkx6.1 $1^{-1-}$ mice (Nelson et al. 2007).

In conclusion, despite great efforts by multiple laboratories, the spatiotemporal aspects of pancreatic and intestinal endocrine subtype specification have remained largely elusive. Although many HD proteins were shown to stimulate gcg promoter or endogenous gcg mRNA expression in cultured cell lines, 'knock-out' studies can only directly verify the involvement of Pax-6 and $\mathrm{Pbx}-1$ in pancreatic $\alpha$-cell development (Table 1). Since $C d x-2^{-/-}$mice are embryonic 
Table 1 Phenotypes of knock-out mice in which a candidate pancreatic $\alpha$-cell homeodomain protein transcription factor is genetically deleted

Alterations in phenotype

Embryonic lethal $(\mathrm{e} 3 \cdot 5-\mathrm{e} 5 \cdot 5)$

Multiple abnormalities in most of the mice

Complete absence of pancreatic endocrine cells

Die shortly after the birth, fail to form pancreatic islet

No detectable defect in pancreatic islet cells

Die at e15-e16, hypoplasia and aplasia for many organs, including pancreas

Pancreatic islet malformation and hyperinsulinemia

Arrested differentiation of $\beta$ cells, fewer glucagon-producing cells

No detectable defect

Increased pancreatic islet volume
Reference

Chawengsaksophak et al. (1997)

Chawengsaksophak et al. (1997)

Pfaff et al. (1996)

St-Onge et al. (1997)

Heller et al. (2004)

Kim et al. (2002)

Kim et al. (2002)

Sussel et al. (1998)

Cai et al. (2001)

Zaiko et al. (2004) lethal, the involvement of $\mathrm{Cdx}-2$ in the genesis and functional maintenance of pancreatic $\boldsymbol{\alpha}$-cells can be assessed only if $\boldsymbol{\alpha}$-cell-specific 'knock-out' mice are generated. Biochemical studies have also revealed physical interactions between different HD proteins and between HD proteins and other transcription factors (which are not covered in this review). This, along with the observations that the same cis-element can be bound by different HD proteins, suggests that HD proteins exert synergistic and redundant effects on the genesis of pancreatic $\alpha$-cells and the expression of the gcg gene.

\section{cAMP and proglucagon expressions}

\section{$C R E$ and other $C A M P$ response elements on the proglucagon promoter}

The effect of cAMP signaling in stimulating gcg expression in both pancreatic islet $\alpha$-cells and intestinal endocrine $\mathrm{L}$ cells has been studied extensively following the recognition of a typical cAMP response element (CRE) within the proximal gcg promoter (Drucker \& Brubaker 1989, Gajic \& Drucker 1993, Drucker et al. 1994, Lu et al. 1996) (Fig. 1). Many studies have been conducted using cultured pancreatic $\alpha$-cell lines or primary pancreatic islet cell cultures of the rodent species (Philippe et al. 1987b, Drucker \& Brubaker 1989, Knepel et al. 1990, Drucker et al. 1991, Schwaninger et al. 1993, Diedrich \& Knepel 1995, Wang et al. 2003). It has been found that in the intestinal GLUTag cell line, either membrane-permeable cAMP analog or cAMP-promoting agents (forskolin or cholera toxin) increased endogenous gcg mRNA expression or GLP-1 production (Drucker et al. 1994). In the fetal rat intestine cell (FRIC) cultures, Brubaker (1988) and Brubaker et al. (1998) demonstrated that both cAMP elevation and PKC activation stimulated glucagon-like immunoreactive peptide (GLI) release. Elevation of cAMP but not PKC activation also stimulated GLI or GLP-1 content (Brubaker 1988, Brubaker et al. 1998).

As shown in Fig. 1, a typical CRE is located between -291 and $-298 \mathrm{bp}$ of the rat gcg promoter. Knepel et al.
(1990) found that this element mediated the stimulatory effect of cAMP elevation on gcg expression in the pancreatic $\boldsymbol{\alpha}$-cells. However, a later study by Gajic \& Drucker (1993) indicated that the deletion of this element only moderately attenuated the stimulatory effect of cAMP on gcg promoter expression when the mouse intestinal STC-1 cell line was examined. Similarly, Lu et al. (1996) found that either deleting or mutating this CRE motif generated only a partial repression on the stimulatory effect of gastrin-releasing peptide on gcg promoter expression in the STC-1 cell line. Furstenau et al. (1999) however, have identified another motif within the G2 enhancer element that could mediate the stimulatory effect of both cAMP and calcium. In addition, Wang et al. 2003 found that activated transcription factor 3 also exerted its stimulatory effect on gcg transcription via interacting with this CRE motif. In studying the stimulatory effect of protein hydrolysates on gcg transcription, Gevrey et al. (2004) revealed the existence of two CRE-like elements that could mediate the stimulatory effect of cAMP and amino acids.

It should be pointed out that although the CRE motif is $100 \%$ conserved among rodent species, in the human gcg promoter this site is CAACGTCA instead of TGACGTCA (Nian et al. 1999). Whether this motif in human gcg gene promoter is capable of interacting with CREB is unknown. Researchers have generated transgenic mice in which the expression of the growth hormone reporter was driven by the $1.6 \mathrm{~kb}$ human gcg promoter (Nian et al. 1999, 2002, Irwin 2001). They demonstrated the evidence of divergence in the mechanisms utilized for tissue-specific regulation of the human and rodent gcg genes (Nian et al. 1999, 2002). Nevertheless, when the human gcg promoter-LUC reporter was transfected into the mouse gcg-expressing cell lines, cAMP elevation significantly stimulated LUC reporter expression (personal communication). This, along with the observations that cAMP elevation may utilize other ciselements to activate gcg promoter transcription, indicates that the typical CRE motif in gcg promoter of the rodent species may not be physiologically important. 
Epac signaling and the gcg gene expression

It has been noticed that the stimulatory effect of cAMP elevation on both gcg promoter and endogenous gcg mRNA expression in the pancreatic $\boldsymbol{\alpha}$-cell line InR 1-G9 was much lower compared with that in the GLUTag and STC-1 cell lines (Drucker et al. 1991, 1994). Later, Chen et al. (2005) reported that InR1-G9 cell line was deficient in protein kinase A (PKA) activity.

Extensive examinations in many different cell lineages have shown that PKA is not the sole mediator of the second messenger cAMP in exerting its versatile biological functions (Richards 2001). In 1998, two groups independently revealed the existence of novel cAMP mediators, namely Epac-1 and Epac-2 (also known as cAMP-GEFs; Kawasaki et al. 1998, de Rooij et al. 1998). Epac molecules are able to mediate the effect of cAMP via activating the Rap-1-Raf-MEK-ERK signaling pathway (Richards 2001, Holz 2004).

The identification of additional cis-elements in gcg promoter that mediate the stimulatory effect of cAMP partially explained why deleting or mutating the CRE motif in the gcg promoter only partially attenuated the effect of cAMP elevation (Furstenau et al. 1999, Gevrey et al. 2004). However, it cannot explain moderate but significant activation of gcg promoter and endogenous gcg mRNA expression by cAMP elevation in the PKA-deficient InR1G9 cell line. Lotfi et al. (2006) have recently reported that Epac-2 was also expressed in the intestinal endocrine L cells. They found that the stimulatory effect of cAMP in the intestinal GLUTag and STC-1 cell lines cannot be blocked by PKA inhibition, and Epac pathway-specific cAMP analog stimulated both gcg promoter and endogenous gcg mRNA expressions in these two cell lines. More recently, Islam \& Jin have also detected Epac- 2 expression in pancreatic $\alpha$-cell lines and primary pancreatic islet cells. Using a dominant negative Epac-2 expression plasmid and the Epac pathway-specific cAMP analog, Islam \& Jin (personal communication) found that Epac signaling was also involved in glucagon production. Ma et al. (2005) have reported that the Epac signaling pathway is involved in glucagon secretion.

It should be pointed out that Epac signaling could be involved in the regulation of the expression and function of transcriptional regulators of the gcg gene, such as the HD protein $\mathrm{Cdx}-2$, whose activation appeared to be dependent on the MEK-ERK signaling cascade (Chen et al. 2005).

\section{Wnt signaling pathway and intestinal gcg gene expression}

\section{Wnt signaling pathway}

The Wnt signaling pathway was initially identified in colon cancer research and embryological studies in Drosophila, Xenopus, and other species (Moon et al. 1997, He et al. 1998, Peifer \& Polakis 2000). Wnt ligands exert their regulatory effect mainly via binding to their receptor Frizzleds and the co-receptor LRP5/6. Many Wnt genes and their receptors are expressed in the pancreatic islets (Heller et al. 2003). The key effector of the canonical Wnt signaling pathway (defined as Wnt pathway hereafter) is the bipartite transcription factor cat/TCF, formed by $\beta$-catenin ( $\beta$-cat) and one of the four TCF factors (TCF-1, LEF-1, TCF-3, and TCF7L2, previous known as TCF-4). Among them, TCF7L2 is the major partner of $\beta$-cat in the intestinal epithelia (Morin et al. 1997, $\mathrm{Yi}$ et al. 2005). Under non-stimulating conditions, the concentration of free $\beta$-cat is tightly controlled by the proteasome-mediated degradation process, with the participation of the tumor suppressor adenomatous polyposis coli, axin, glycogen synthase kinase-3 (GSK-3), and casein kinase$1 \alpha$ (Doble \& Woodgett 2003, Zeng et al. 2005). In response to Wnt ligand stimulation, free $\beta$-cat accumulates, leading to the formation of the cat/TCF complex and the activation of cat/TCF downstream target genes. In addition, lithium and other inhibitors of GSK-3 may also stimulate the expression of downstream target genes of the Wnt signaling pathway, mainly through free $\beta$-cat accumulation (Stambolic et al. 1996).

\section{Wnt signaling pathway and intestinal gcg expression}

The expression of gcg mRNA in the intestinal STC-1 and GLUTag cell lines and in the primary FRIC cultures could be activated by lithium (Ni et al. 2003). The activation evidently involves the effector of the Wnt signaling pathway because a constitutively active $\beta$-cat molecule (S33Y mutant) stimulated gcg promoter expression, and dominant negative TCF7L2 blocked the stimulatory effect of lithium on gcg promoter and gcg mRNA expression and GLP-1 production in the GLUTag cell line (Yi et al. 2005). In addition, the expression of dominant negative TCF-4 also substantially inhibited basal gcg mRNA expression in the GLUTag cell line (Yi et al. 2005). They then determined the role of a TCF factorbinding motif within the G2 enhancer element of the gcg promoter. Because this region was previously demonstrated by Furstanau et al. as a cis-element that mediates the effect of cAMP and calcium on gcg promoter expression this raised the interesting question as to whether Wnt signaling pathway crosstalks with the cAMP-PKA signaling in the intestinal endocrine L cells (Yi et al. 2005).

Opposite effect of insulin on gcg expression in pancreatic $\alpha$-cells versus intestinal $L$ cells

Insulin has been shown to repress pancreatic gcg mRNA expression by Philippe $(1989,1991)$. This repression is physiologically important because gcg expression in pancreatic islets leads to the production of glucagon, the major counterregulatory hormone of insulin. Philippe (1991) showed that the repression is mediated by a cis-element within the G3 element of the rat gcg promoter. Schinner et al. (2005) found that $\mathrm{PKB}$ was sufficient to mimic the inhibitory effect 
of insulin in the pancreatic $\alpha$-cells on gcg expression. More recently, McKinnon et al. (2006) found that insulin treatment in the $\alpha \mathrm{TC} 1-9$ cell line caused endogenous FOXO1 to translocate from the nucleus to the cytoplasm. Furthermore, in the absence of insulin, FOXO1 silencing by RNA interference reduced gcg mRNA expression by $>40 \%$ (McKinnon et al. 2006). The neuropeptide hormone orexin $A$, however, was shown to inhibit gcg expression in the InR1-G9 cells, possibly through 1) decreasing cAMP and calcium levels and 2) increasing PKB, PDK-1, and FOXO1 phosphorylations (Goncz et al. 2007).

More recently, Yi et al. (2008) reported that in the intestinal endocrine L cells, insulin at pathological dosages stimulated gcg mRNA expression and GLP-1 production. Furthermore, in the hyperglycemic and insulin resistance MKR mice, gcg mRNA expression and GLP-1 content in the distal ileum were shown to be significantly higher than that of sex- and age-matched controls (Yi et al. 2008). More interestingly, insulin was demonstrated to utilize the same cis- and transelements in stimulating intestinal gcg expression, supporting the existence of crosstalk between insulin and Wnt signaling pathways (Yi et al. 2008).

Exactly how insulin exerts opposite effects on the expression of the same gcg gene in the intestinal endocrine $\mathrm{L}$ cells versus pancreatic $\alpha$-cells is not clear. However, it appears that different signaling cascades are involved in these two cell lineages. As demonstrated by Schinner et al. (2005) in the pancreatic $\alpha$-cells, the repressive effect of insulin on gcg expression relies on PKB activity. In the intestinal $\mathrm{L}$ cells, it is unlikely that PKB activity is involved in insulin-stimulated gcg promoter transcription (Yi et al. 2008).

\section{TCF7L2 as a potential T2D susceptible gene}

A study by Grant et al. (2006) indicated that in three different ethnic groups, individuals carrying certain single nucleotide polymorphisms (SNP) in the TCF7L2 gene are more susceptible to the development of T2D. This discovery has drawn great attention globally. Detailed information on this line of research has been summarized in a few review articles in 2007 (Elbein 2007, Florez 2007, Frayling 2007, Grarup \& Andersen 2007, Owen \& McCarthy 2007). To date, studies have indicated that T2D susceptible TCF7L2 SNP carriers show reduced postprandial insulin secretion (Schafer et al. 2007). In addition, detection of TCF7L2 expression in human pancreatic $\beta$-cells has been reported recently and this transcription factor plays a role in insulin production and secretion, as well as pancreatic $\beta$-cell growth (Loos et al. 2007, Lyssenko et al. 2007, Shu et al. 2007, Liu \& Habener 2008). Interestingly, to date, all of the identified T2D susceptible TCF7L2 SNPs are located within the intron regions of the TCF7L2 gene; therefore, it is likely that the polymorphisms affect TCF7L2 gene expression, but not its function. Since TCF7L2 ${ }^{-/-}$mice die shortly after their birth, due to extensive defects of intestinal stem cell development (Korinek et al. 1998); to further investigate the role of TCF7L2 in the genesis and maturation of pancreatic islet cells and intestinal endocrine L cells would require cell-type-specific 'knockout' approaches.

\section{Summary and perspective}

We have learned that nearly a dozen homeobox genes are potentially involved in the expression of the gcg gene, although 'knock-out' approaches have only directly confirmed the roles for Pax-6 and Pbx-1. It is likely that this is due to the existence of redundant mechanisms for compensation. To fully understand the spatiotemporal aspects of pancreatic $\alpha$-cell specification, more transgenic mouse work using the approaches including 'conditional knock-out' (Cdx-2, for example) and 'double knock-out' (Cdx-2 and Brn-4, for example) needs to be conducted.

We have learned that multiple cis-elements are implicated in mediating the stimulatory effect of cAMP elevation on gcg expression in pancreatic and intestinal gcg-producing cells, possibly involving both the PKA and Epac signaling pathways. It should be pointed out that crosstalk between Wnt signaling and signaling pathways that are activated by G-protein-coupled receptors have drawn our attention recently (Force et al. 2007, Liu $\&$ Habener 2008). Whether certain hormones and neurotransmitters exert their effects on gcg expression via crosstalking with the Wnt signaling pathway remains to be investigated. Figure 2 summarizes the interpretations of how the signaling molecules and HD proteins are involved in regulating gcg transcription, including the newly recognized Wnt signaling.

GLP-1 is a powerful therapeutic agent for T2D and potentially for several other disorders. In T2D patients, GLP-1 secretion could be reduced (Vilsboll et al. 2001). Expanding our understanding on the mechanisms underlying endogenous gcg expression, therefore, will be helpful for the development of novel approaches in treating T2D and other disorders. These studies should also lead to the discovery of additional diagnostic and prognostic factors. It also should be further emphasized that during embryonic stages, pancreatic gcg expression may lead to the production of GLP-1, which could play a role in pancreatic $\beta$-cell genesis and maturation (Wilson et al. 2002). Indeed, Thyssen et al. (2006) have shown that in streptozotocin (STZ)-treated rats, $\beta$-cell regeneration is associated with increased pancreatic levels of GLP-1. Therefore, the exploration of spatiotemporal aspects of pancreatic $\alpha$-cell generation and maturation should not be left behind too much. Interestingly, both $G L P-1 R^{-/-}$and $P C 1 / 3^{-1-}$ mice develop pancreatic $\beta$-cells (Scrocchi et al. 1996, Zhu et al. 2002), suggesting that although pancreatic GLP-1 may be important, GLP-1 signaling is not absolutely required for pancreatic islet development.

Since glucagon produced in pancreatic $\boldsymbol{\alpha}$-cells and GLP-1 produced in intestinal L cells exert opposite effects on blood glucose homeostasis, one may expect the existence of cell-typespecific mechanisms underlying gcg transcription. Comparing reporter gene expression of the transgenic mice generated by 
Efrat et al. (1988) with those generated by Lee et al. (1992) led to the suggestion that the DNA sequence from $-1 \cdot 3$ to $-2 \cdot 3 \mathrm{~kb}$ of rat gcg promoter is required for its expression in intestinal L cells (Jin \& Drucker 1995). In vitro transfection studies, however, could not locate a cis-element within this region that mediates gcg promote expression via an intestinal L-cell-specific transelement (Jin \& Drucker 1995). Nevertheless, recent studies have revealed cell-type-specific activation of gcg expression by the effectors of the Wnt signaling pathway and the crosstalk between Wnt and insulin signaling pathways (Yi et al. 2005). Whether Wnt signaling and crosstalk between Wnt and other signaling pathways are involved in the genesis of intestinal $\mathrm{L}$ cells, and the process involves the DNA sequence between $-1 \cdot 3$ and $-2.3 \mathrm{~kb}$ remain to be investigated.

\section{Declaration of Interest}

The author declares that there is no conflict of interest that would prejudice the impartiality of this scientific work.

\section{Funding}

The Canadian Institutes of Health Research (CIHR 68991 and 62746), Canadian Diabetes Association (CDA), and Banting and Best Diabetes Centre (BBDC) provided operating funding support, as well as fellowship and studentship support for the author's research trainees.

\section{Acknowledgements}

The author would like to thank Dr David Irwin for his valuable suggestions.

\section{References}

Abraham EJ, Leech CA, Lin JC, Zulewski H \& Habener JF 2002 Insulinotropic hormone glucagon-like peptide-1 differentiation of human pancreatic islet-derived progenitor cells into insulin-producing cells. Endocrinology 143 3152-3161.

Bell GI, Sanchez-Pescador R, Laybourn PJ \& Najarian RC 1983a Exon duplication and divergence in the human preproglucagon gene. Nature 304 368-371.

$\backslash$ kern-2ptBell GI, Santerre RF \& Mullenbach GT $1983 b$ Hamster preproglucagon contains the sequence of glucagon and two related peptides. Nature 302 716-718.

Berthelsen J, Kilstrup-Nielsen C, Blasi F, Mavilio F \& Zappavigna V 1999 The subcellular localization of PBX1 and EXD proteins depends on nuclear import and export signals and is modulated by association with PREP1 and HTH. Genes and Development 13 946-953.

Bonner-Weir S \& Weir GC 2005 New sources of pancreatic beta-cells. Nature Biotechnology 23 857-861.

Brubaker PL 1988 Control of glucagon-like immunoreactive peptide secretion from fetal rat intestinal cultures. Endocrinology 123 220-226.

Brubaker PL \& Drucker DJ 2004 Minireview: glucagon-like peptides regulate cell proliferation and apoptosis in the pancreas, gut, and central nervous system. Endocrinology 145 2653-2659.

Brubaker PL, Schloos J \& Drucker DJ 1998 Regulation of glucagon-like peptide-1 synthesis and secretion in the GLUTag enteroendocrine cell line. Endocrinology 139 4108-4114.
Burcelin R, Katz EB \& Charron MJ 1996 Molecular and cellular aspects of the glucagon receptor: role in diabetes and metabolism. Diabetes and Metabolism 22 373-396.

Cai J, Qi Y, Wu R, Modderman G, Fu H, Liu R \& Qiu M 2001 Mice lacking the Nkx6.2 (Gtx) homeodomain transcription factor develop and reproduce normally. Molecular and Cellular Biology 21 4399-4403.

Campos RV, Lee YC \& Drucker DJ 1994 Divergent tissue-specific and developmental expression of receptors for glucagon and glucagon-like peptide-1 in the mouse. Endocrinology 134 2156-2164.

Chawengsaksophak K, James R, Hammond VE, Kontgen F \& Beck F 1997 Homeosis and intestinal tumours in Cdx2 mutant mice. Nature 386 84-87.

Chen L, Wang P, Andrade CF, Zhao IY, Dube PE, Brubaker PL, Liu M \& Jin T 2005 PKA independent and cell type specific activation of the expression of caudal homeobox gene Cdx-2 by cyclic AMP. FEBS Journal 272 2746-2759.

Christophe J 1996 Glucagon and its receptor in various tissues. Annals of the New York Academy of Sciences 805 31-42 discussion 42-33.

Diedrich T \& Knepel W 1995 Interaction of the transcription factor CREB with pancreatic islet cell-specific enhancer elements. Biological Chemistry Hoppe-Seyler 376 39-44.

Ding Q, Xia W, Liu JC, Yang JY, Lee DF, Xia J, Bartholomeusz G, Li Y, Pan Y, Li Z et al. 2005 Erk associates with and primes GSK-3beta for its inactivation resulting in upregulation of beta-catenin. Molecular Cell 19 159-170.

Doble BW \& Woodgett JR 2003 GSK-3: tricks of the trade for a multi-tasking kinase. Journal of Cell Science 116 1175-1186.

Dong J, Asa SL \& Drucker DJ 1991 Islet cell and extrapancreatic expression of the LIM domain homeobox gene isl-1. Molecular Endocrinology $\mathbf{5}$ 1633-1641.

Doyle ME \& Egan JM 2007 Mechanisms of action of glucagon-like peptide 1 in the pancreas. Pharmacology and Therapeutics 113 546-593.

Drucker DJ 2001 Minireview: the glucagon-like peptides. Endocrinology 142 521-527.

Drucker DJ 2002 Biological actions and therapeutic potential of the glucagonlike peptides. Gastroenterology 122 531-544.

Drucker DJ 2006 The biology of incretin hormones. Cell Metabolism 3 153-165.

Drucker DJ \& Brubaker PL 1989 Proglucagon gene expression is regulated by a cyclic AMP-dependent pathway in rat intestine. PNAS 86 3953-3957.

Drucker DJ, Campos R, Reynolds R, Stobie K \& Brubaker PL 1991 The rat glucagon gene is regulated by a protein kinase A-dependent pathway in pancreatic islet cells. Endocrinology 128 394-400.

Drucker DJ, Jin T, Asa SL, Young TA \& Brubaker PL 1994 Activation of proglucagon gene transcription by protein kinase-A in a novel mouse enteroendocrine cell line. Molecular Endocrinology 8 1646-1655.

Drucker DJ, Erlich P, Asa SL \& Brubaker PL 1996 Induction of intestinal epithelial proliferation by glucagon-like peptide 2. PNAS 93 7911-7916.

Efrat S, Teitelman G, Anwar M, Ruggiero D \& Hanahan D 1988 Glucagon gene regulatory region directs oncoprotein expression to neurons and pancreatic alpha cells. Neuron $1605-613$.

Elbein SC 2007 Evaluation of polymorphisms known to contribute to risk for diabetes in African and African-American populations. Current Opinion in Clinical Nutrition and Metabolic Care 10 415-419.

Ericson J, Thor S, Edlund T, Jessell TM \& Yamada T 1992 Early stages of motor neuron differentiation revealed by expression of homeobox gene Islet-1. Science 256 1555-1560.

Flock G \& Drucker DJ 2002 Pax-2 activates the proglucagon gene promoter but is not essential for proglucagon gene expression or development of proglucagon-producing cell lineages in the murine pancreas or intestine. Molecular Endocrinology 16 2349-2359.

Florez JC 2007 The new type 2 diabetes gene TCF7L2. Current Opinion in Clinical Nutrition and Metabolic Care 10 391-396.

Force T, Woulfe K, Koch WJ \& Kerkela R 2007 Molecular scaffolds regulate bidirectional crosstalk between Wnt and classical seven-transmembranedomain receptor signaling pathways. Science's STKE pe41.

Frayling TM 2007 A new era in finding type 2 diabetes genes-the unusual suspects. Diabetic Medicine 24 696-701. 
Furstenau U, Schwaninger M, Blume R, Jendrusch EM \& Knepel W 1999 Characterization of a novel calcium response element in the glucagon gene. Journal of Biological Chemistry 274 5851-5860.

Gajic D \& Drucker DJ 1993 Multiple cis-acting domains mediate basal and adenosine $3^{\prime}, 5^{\prime}$-monophosphate-dependent glucagon gene transcription in a mouse neuroendocrine cell line. Endocrinology 132 1055-1062.

German MS, Wang J, Chadwick RB \& Rutter WJ 1992 Synergistic activation of the insulin gene by a LIM-homeo domain protein and a basic helix-loophelix protein: building a functional insulin minienhancer complex. Genes and Development 6 2165-2176.

Gevrey JC, Malapel M, Philippe J, Mithieux G, Chayvialle JA, Abello J \& Cordier-Bussat M 2004 Protein hydrolysates stimulate proglucagon gene transcription in intestinal endocrine cells via two elements related to cyclic AMP response element. Diabetologia 47 926-936.

Goncz E, Strowski MZ, Grotzinger C, Nowak KW, Kaczmarek P, Sassek M, Mergler S, El-Zayat BF, Theodoropoulou M, Stalla GK et al. 2008 OrexinA inhibits glucagon secretion and gene expression through a Foxo1dependent pathway. Endocrinology 149 1618-1626.

Grant SF, Thorleifsson G, Reynisdottir I, Benediktsson R, Manolescu A, Sainz J, Helgason A, Stefansson H, Emilsson V, Helgadottir A et al. 2006 Variant of transcription factor 7-like 2 (TCF7L2) gene confers risk of type 2 diabetes. Nature Genetics 38 320-323.

Grarup N \& Andersen G 2007 Gene-environment interactions in the pathogenesis of type 2 diabetes and metabolism. Current Opinion in Clinical Nutrition and Metabolic Care 10 420-426.

Habener JF, Kemp DM \& Thomas MK 2005 Minireview: transcriptional regulation in pancreatic development. Endocrinology 146 1025-1034.

He TC, Sparks AB, Rago C, Hermeking H, Zawel L, da Costa LT, Morin PJ, Vogelstein B \& Kinzler KW 1998 Identification of c-MYC as a target of the APC pathway. Science 281 1509-1512.

Heinrich G, Gros P, Lund PK, Bentley RC \& Habener JF 1984 Preproglucagon messenger ribonucleic acid: nucleotide and encoded amino acid sequences of the rat pancreatic complementary deoxyribonucleic acid. Endocrinology 115 2176-2181.

Heller RS, Klein T, Ling Z, Heimberg H, Katoh M, Madsen OD \& Serup P 2003 Expression of Wnt, Frizzled, sFRP, and DKK genes in adult human pancreas. Gene Expression 11 141-147.

Heller RS, Stoffers DA, Liu A, Schedl A, Crenshaw EB, III, Madsen OD \& Serup P 2004 The role of Brn4/Pou3f4 and Pax6 in forming the pancreatic glucagon cell identity. Developmental Biology 268 123-134.

Henseleit KD, Nelson SB, Kuhlbrodt K, Hennings JC, Ericson J \& Sander M 2005 NKX6 transcription factor activity is required for $\alpha$ - and $\beta$-cell development in the pancreas. Development 132 3139-3149.

Herzig S, Fuzesi L \& Knepel W 2000 Heterodimeric Pbx-Prep1 homeodomain protein binding to the glucagon gene restricting transcription in a cell type-dependent manner. Journal of Biological Chemistry 275 27989-27999.

Holst JJ 2006 Glucagon-like peptide-1: from extract to agent. The Claude Bernard Lecture, 2005. Diabetologia 49 253-260.

Holz GG 2004 New insights concerning the glucose-dependent insulin secretagogue action of glucagon-like peptide- 1 in pancreatic $\beta$-cells. Hormone and Metabolic Research 36 787-794.

Hussain MA \& Habener JF 1999 Glucagon gene transcription activation mediated by synergistic interactions of pax- 6 and $c d x-2$ with the p300 co-activator. Journal of Biological Chemistry 274 28950-28957.

Hussain MA, Lee J, Miller CP \& Habener JF 1997 POU domain transcription factor brain 4 confers pancreatic alpha-cell-specific expression of the proglucagon gene through interaction with a novel proximal promoter G1 element. Molecular and Cellular Biology 17 7186-7194.

Hussain MA, Miller CP \& Habener JF 2002 Brn-4 transcription factor expression targeted to the early developing mouse pancreas induces ectopic glucagon gene expression in insulin-producing beta cells. Journal of Biological Chemistry 277 16028-16032.

Irwin DM 2001 Molecular evolution of proglucagon. Regulatory Peptides 98 $1-12$.

Jelinek LJ, Lok S, Rosenberg GB, Smith RA, Grant FJ, Biggs S, Bensch PA, Kuijper JL, Sheppard PO, Sprecher CA et al. 1993 Expression cloning and signaling properties of the rat glucagon receptor. Science 259 1614-1616.
Jeppesen PB 2003 Clinical significance of GLP-2 in short-bowel syndrome. Journal of Nutrition 133 3721-3724.

Jin T \& Drucker DJ 1995 The proglucagon gene upstream enhancer contains positive and negative domains important for tissue-specific proglucagon gene transcription. Molecular Endocrinology 9 1306-1320.

Jin T \& Drucker DJ 1996 Activation of proglucagon gene transcription through a novel promoter element by the caudal-related homeodomain protein cdx-2/3. Molecular and Cellular Biology 16 19-28.

Jin T, Trinh DK, Wang F \& Drucker DJ 1997 The caudal homeobox protein $\mathrm{cdx}-2 / 3$ activates endogenous proglucagon gene expression in InR1-G9 islet cells. Molecular Endocrinology 11 203-209.

Karlsson O, Thor S, Norberg T, Ohlsson H \& Edlund T 1990 Insulin gene enhancer binding protein Isl-1 is a member of a novel class of proteins containing both a homeo- and a Cys-His domain. Nature 344 879-882.

Kawasaki H, Springett GM, Mochizuki N, Toki S, Nakaya M, Matsuda M, Housman DE \& Graybiel AM 1998 A family of cAMP-binding proteins that directly activate Rap1. Science 282 2275-2279.

Kieffer TJ 2004 Gastro-intestinal hormones GIP and GLP-1. Annales d'Endocrinologie 65 13-21.

Kim SK, Selleri L, Lee JS, Zhang AY, Gu X, Jacobs Y \& Cleary ML 2002 Pbx1 inactivation disrupts pancreas development and in Ipf1-deficient mice promotes diabetes mellitus. Nature Genetics 30 430-435.

Knepel W, Chafitz J \& Habener JF 1990 Transcriptional activation of the rat glucagon gene by the cyclic AMP-responsive element in pancreatic islet cells. Molecular and Cellular Biology 10 6799-6804.

Korinek V, Barker N, Moerer P, van Donselaar E, Huls G, Peters PJ \& Clevers H 1998 Depletion of epithelial stem-cell compartments in the small intestine of mice lacking Tcf-4. Nature Genetics 19 379-383.

Laser B, Meda P, Constant I \& Philippe J 1996 The caudal-related homeodomain protein $\mathrm{Cdx}-2 / 3$ regulates glucagon gene expression in islet cells. Journal of Biological Chemistry 271 28984-28994.

Lee YC, Asa SL \& Drucker DJ 1992 Glucagon gene 5'-flanking sequences direct expression of simian virus 40 large $\mathrm{T}$ antigen to the intestine, producing carcinoma of the large bowel in transgenic mice. Journal of Biological Chemistry 267 10705-10708.

List JF \& Habener JF 2004 Glucagon-like peptide 1 agonists and the development and growth of pancreatic beta-cells. American Journal of Physiology. Endocrinology and Metabolism 286 E875-E881.

Liu Z \& Habener JF 2008. Glucagon-like peptide-1 activation of TCF7L2dependent Wnt signaling enhances pancreatic $\beta$-cell proliferation. Journal of Biological Chemistry 283 8723-8735.

Liu T, Branch DR \& Jin T $2006 \mathrm{Pbx} 1$ is a co-factor for Cdx-2 in regulating proglucagon gene expression in pancreatic A cells. Molecular and Cellular Endocrinology 249 140-149.

Loos RJ, Franks PW, Francis RW, Barroso I, Gribble FM, Savage DB, Ong KK, O'Rahilly S \& Wareham NJ 2007 TCF7L2 polymorphisms modulate proinsulin levels and beta-cell function in a British Europid population. Diabetes 56 1943-1947.

Lopez LC, Frazier ML, Su CJ, Kumar A \& Saunders GF 1983 Mammalian pancreatic preproglucagon contains three glucagon-related peptides. PNAS 80 5485-5489.

Lotfi S, Li Z, Sun J, Zuo Y, Lam PP, Kang Y, Rahimi M, Islam D, Wang P, Gaisano HY \& Jin T 2006 Role of the exchange protein directly activated by cyclic adenosine $5^{\prime}$-monophosphate (Epac) pathway in regulating proglucagon gene expression in intestinal endocrine L cells. Endocrinology $1473727-3736$.

Lu F, Jin T \& Drucker DJ 1996 Proglucagon gene expression is induced by gastrin-releasing peptide in a mouse enteroendocrine cell line. Endocrinology 137 3710-3716.

Lund PK, Goodman RH, Dee PC \& Habener JF 1982 Pancreatic preproglucagon cDNA contains two glucagon-related coding sequences arranged in tandem. PNAS 79 345-349.

Lyssenko V, Lupi R, Marchetti P, Del Guerra S, Orho-Melander M, Almgren P, Sjogren M, Ling C, Eriksson KF, Lethagen AL et al. 2007 Mechanisms by which common variants in the TCF7L2 gene increase risk of type 2 diabetes. Journal of Clinical Investigation 117 2155-2163. 
Ma X, Zhang Y, Gromada J, Sewing S, Berggren PO, Buschard K, Salehi A, Vikman J, Rorsman P \& Eliasson L 2005 Glucagon stimulates exocytosis in mouse and rat pancreatic $\alpha$-cells by binding to glucagon receptors. Molecular Endocrinology 19 198-212.

Malbon CC 2004 Frizzleds: new members of the superfamily of G-proteincoupled receptors. Frontiers in Bioscience 9 1048-1058.

McKinnon CM, Ravier MA \& Rutter GA 2006 FoxO1 is required for the regulation of preproglucagon gene expression by insulin in pancreatic alphaTC1-9 cells. Journal of Biological Chemistry 281 39358-39369.

Meeran K, O'Shea D, Edwards CM, Turton MD, Heath MM, Gunn I, Abusnana S, Rossi M, Small CJ, Goldstone AP et al. 1999 Repeated intracerebroventricular administration of glucagon-like peptide-1-(7-36) amide or exendin-(9-39) alters body weight in the rat. Endocrinology 140 244-250.

Moon RT, Brown JD \& Torres M 1997 WNTs modulate cell fate and behavior during vertebrate development. Trends in Genetics 13 157-162.

Morin PJ, Sparks AB, Korinek V, Barker N, Clevers H, Vogelstein B \& Kinzler KW 1997 Activation of $\beta$-catenin-Tcf signaling in colon cancer by mutations in $\beta$-catenin or APC. Science 275 1787-1790.

Murphy KG, Dhillo WS \& Bloom SR 2006 Gut peptides in the regulation of food intake and energy homeostasis. Endocrine Reviews 27 719-727.

Nelson SB, Schaffer AE \& Sander M 2007 The transcription factors Nkx6.1 and Nkx6.2 possess equivalent activities in promoting beta-cell fate specification in Pdx1+ pancreatic progenitor cells. Development 134 2491-2500.

Ni Z, Anini Y, Fang X, Mills G, Brubaker PL \& Jin T 2003 Transcriptional activation of the proglucagon gene by lithium and beta-catenin in intestinal endocrine L cells. Journal of Biological Chemistry 278 1380-1387.

Nian M, Drucker DJ \& Irwin D 1999 Divergent regulation of human and rat proglucagon gene promoters in vivo. American Journal of Physiology 277 G829-G837.

Nian M, Gu J, Irwin DM \& Drucker DJ 2002 Human glucagon gene promoter sequences regulating tissue-specific versus nutrient-regulated gene expression. American Journal of Physiology Regulatory, Integrative and Comparative Physiology 282 R173-R183.

Owen KR \& McCarthy MI 2007 Genetics of type 2 diabetes. Current Opinion in Genetics and Development 17 239-244.

Pedersen JK, Nelson SB, Jorgensen MC, Henseleit KD, Fujitani Y, Wright CV, Sander M \& Serup P 2005 Endodermal expression of Nkx6 genes depends differentially on Pdx1. Developmental Biology 288 487-501.

Peifer M \& Polakis P 2000 Wnt signaling in oncogenesis and embryogenesis a look outside the nucleus. Science 287 1606-1609.

Peng SY, Wang WP, Meng J, Li T, Zhang H, Li YM, Chen P, Ma KT \& Zhou CY 2005 ISL1 physically interacts with BETA2 to promote insulin gene transcriptional synergy in non-beta cells. Biochimica et Biophysica Acta 1731 154-159.

Pfaff SL, Mendelsohn M, Stewart CL, Edlund T \& Jessell TM 1996 Requirement for LIM homeobox gene Isl1 in motor neuron generation reveals a motor neuron-dependent step in interneuron differentiation. Cell 84 309-320.

Philippe J 1989 Glucagon gene transcription is negatively regulated by insulin in a hamster islet cell line. Journal of Clinical Investigation 84 672-677.

Philippe J 1991 Insulin regulation of the glucagon gene is mediated by an insulin-responsive DNA element. PNAS 88 7224-7227.

Philippe J, Drucker DJ, Chick WL \& Habener JF 1987a Transcriptional regulation of genes encoding insulin, glucagon, and angiotensinogen by sodium butyrate in a rat islet cell line. Molecular and Cellular Biology 7 560-563.

Philippe J, Drucker DJ \& Habener JF $1987 b$ Glucagon gene transcription in an islet cell line is regulated via a protein kinase C-activated pathway. Journal of Biological Chemistry 262 1823-1828.

Richards JS 2001 New signaling pathways for hormones and cyclic adenosine $3^{\prime}, 5^{\prime}$-monophosphate action in endocrine cells. Molecular Endocrinology 15 209-218.

Ritz-Laser B, Estreicher A, Klages N, Saule S \& Philippe J 1999 Pax-6 and $\mathrm{Cdx}-2 / 3$ interact to activate glucagon gene expression on the G1 control element. Journal of Biological Chemistry 274 4124-4132.

Ritz-Laser B, Estreicher A, Gauthier B \& Philippe J 2000 The paired homeodomain transcription factor Pax-2 is expressed in the endocrine pancreas and transactivates the glucagon gene promoter. Journal of Biological Chemistry 275 32708-32715.
Ritz-Laser B, Estreicher A, Gauthier BR, Mamin A, Edlund H \& Philippe J 2002 The pancreatic $\beta$-cell-specific transcription factor Pax-4 inhibits glucagon gene expression through Pax-6. Diabetologia 45 97-107.

Ritz-Laser B, Mamin A, Brun T, Avril I, Schwitzgebel VM \& Philippe J 2005 The zinc finger-containing transcription factor Gata-4 is expressed in the developing endocrine pancreas and activates glucagon gene expression. Molecular Endocrinology 19 759-770.

de Rooij J, Zwartkruis FJ, Verheijen MH, Cool RH, Nijman SM, Wittinghofer A \& Bos JL 1998 Epac is a Rap1 guanine-nucleotideexchange factor directly activated by cyclic AMP. Nature 396 474-477.

Sander M, Neubuser A, Kalamaras J, Ee HC, Martin GR \& German MS 1997 Genetic analysis reveals that PAX6 is required for normal transcription of pancreatic hormone genes and islet development. Genes and Development 11 1662-1673.

Sander M, Sussel L, Conners J, Scheel D, Kalamaras J, Dela Cruz F, Schwitzgebel V, Hayes-Jordan A \& German M 2000 Homeobox gene Nkx6.1 lies downstream of Nkx2.2 in the major pathway of beta-cell formation in the pancreas. Development 127 5533-5540.

Schafer SA, Tschritter O, Machicao F, Thamer C, Stefan N, Gallwitz B, Holst JJ, DekkerJM, T’Hart LM, Nijpels G et al. 2007 Impaired glucagon-like peptide1-induced insulin secretion in carriers of transcription factor 7-like 2 (TCF7L2) gene polymorphisms. Diabetologia 50 2443-2450.

Schinner S, Barthel A, Dellas C, Grzeskowiak R, Sharma SK, Oetjen E, Blume R \& Knepel W 2005 Protein kinase B activity is sufficient to mimic the effect of insulin on glucagon gene transcription. Journal of Biological Chemistry 280 7369-7376.

Schisler JC, Jensen PB, Taylor DG, Becker TC, Knop FK, Takekawa S, German M, Weir GC, Lu D, Mirmira RG \& Newgard CB 2005 The Nkx6.1 homeodomain transcription factor suppresses glucagon expression and regulates glucose-stimulated insulin secretion in islet beta cells. PNAS 102 7297-7302.

Schwaninger M, Lux G, Blume R, Oetjen E, Hidaka H \& Knepel W 1993 Membrane depolarization and calcium influx induce glucagon gene transcription in pancreatic islet cells through the cyclic AMP-responsive element. Journal of Biological Chemistry 268 5168-5177.

Scrocchi LA, Brown TJ, MaClusky N, Brubaker PL, Auerbach AB, Joyner AL \& Drucker DJ 1996 Glucose intolerance but normal satiety in mice with a null mutation in the glucagon-like peptide 1 receptor gene. Nature Medicine 2 1254-1258.

Shu L, Sauter NS, Schulthess FT, Matveyenko AV, Oberholzer J \& Maedler K 2008 TCF7L2 regulates -cell survival and function in human pancreatic islets. Diabetes $\mathbf{5 7}$ 645-653.

Sinclair EM \& Drucker DJ 2005 Proglucagon-derived peptides: mechanisms of action and therapeutic potential. Physiology 20 357-365.

Stambolic V, Ruel L \& Woodgett JR 1996 Lithium inhibits glycogen synthase kinase- 3 activity and mimics wingless signalling in intact cells. Current Biology 6 1664-1668.

St-Onge L, Sosa-Pineda B, Chowdhury K, Mansouri A \& Gruss P 1997 Pax6 is required for differentiation of glucagon-producing alpha-cells in mouse pancreas. Nature 387 406-409.

Stoykova A, Fritsch R, Walther C \& Gruss P 1996 Forebrain patterning defects in small eye mutant mice. Development 122 3453-3465.

Sussel L, Kalamaras J, Hartigan-O'Connor DJ, Meneses JJ, Pedersen RA, Rubenstein JL \& German MS 1998 Mice lacking the homeodomain transcription factor $\mathrm{Nkx} 2.2$ have diabetes due to arrested differentiation of pancreatic $\beta$-cells. Development 125 2213-2221.

Thor S, Ericson J, Brannstrom T \& Edlund T 1991 The homeodomain LIM protein Isl-1 is expressed in subsets of neurons and endocrine cells in the adult rat. Neuron 7 881-889.

Thyssen S, Arany E \& Hill DJ 2006 Ontogeny of regeneration of beta-cells in the neonatal rat after treatment with streptozotocin. Endocrinology 147 2346-2356.

Trinh DK, Zhang K, Hossain M, Brubaker PL \& Drucker DJ 2003 Pax-6 activates endogenous proglucagon gene expression in the rodent gastrointestinal epithelium. Diabetes 52 425-433.

Turton MD, O'Shea D, Gunn I, Beak SA, Edwards CM, Meeran K, Choi SJ, Taylor GM, Heath MM, Lambert PD et al. 1996 A role for glucagon-like peptide- 1 in the central regulation of feeding. Nature 379 69-72. 
Vallejo M, Penchuk L \& Habener JF 1992 Somatostatin gene upstream enhancer element activated by a protein complex consisting of CREB, Isl1-like, and alpha-CBF-like transcription factors. Journal of Biological Chemistry 267 12876-12884.

Vilsboll T, Krarup T, Deacon CF, Madsbad S \& Holst JJ 2001 Reduced postprandial concentrations of intact biologically active glucagon-like peptide 1 in type 2 diabetic patients. Diabetes 50 609-613.

Wang M \& Drucker DJ 1995 The LIM domain homeobox gene isl-1 is a positive regulator of islet cell-specific proglucagon gene transcription. Journal of Biological Chemistry 270 12646-12652.

Wang H, Maechler P, Ritz-Laser B, Hagenfeldt KA, Ishihara H, Philippe J \& Wollheim CB $2001 \mathrm{Pdx} 1$ level defines pancreatic gene expression pattern and cell lineage differentiation. Journal of Biological Chemistry 276 25279-25286.

Wang J, Cao Y \& Steiner DF 2003 Regulation of proglucagon transcription by activated transcription factor (ATF) 3 and a novel isoform, ATF3b, through the cAMP-response element/ATF site of the proglucagon gene promoter. Journal of Biological Chemistry 278 32899-32904.

Wang P, Liu T, Li Z, Ma X \& Jin T 2006 Redundant and synergistic effect of $\mathrm{Cdx}-2$ and Brn-4 on regulating proglucagon gene expression. Endocrinology 147 1950-1958.

Wideman RD, Yu IL, Webber TD, Verchere CB, Johnson JD, Cheung AT \& Kieffer TJ 2006 Improving function and survival of pancreatic islets by endogenous production of glucagon-like peptide 1 (GLP-1). PNAS 103 13468-13473.

Wideman RD, Covey SD, Webb GC, Drucker DJ \& Kieffer TJ 2007 A switch from prohormone convertase (PC)-2 to $\mathrm{PC} 1 / 3$ expression in transplanted alpha-cells is accompanied by differential processing of proglucagon and improved glucose homeostasis in mice. Diabetes 56 2744-2752.
Wilson ME, Kalamaras JA \& German MS 2002 Expression pattern of IAPP and prohormone convertase $1 / 3$ reveals a distinctive set of endocrine cells in the embryonic pancreas. Mechanism of Development 115 171-176.

Xu F, Li H \& Jin T 1999 Cell type-specific autoregulation of the Caudal-related homeobox gene Cdx-2/3. Journal of Biological Chemistry 274 34310-34316.

Yi F, Brubaker PL \& Jin T 2005 TCF-4 mediates cell type-specific regulation of proglucagon gene expression by $\beta$-catenin and glycogen synthase kinase3beta. Journal of Biological Chemistry 280 1457-1464.

Yi F, Sun J, Lim GE, Fantus IG, Brubaker PL \& Jin T 2008. Crosstalk between the insulin and Wnt signaling pathways: evidence from intestinal endocrine L cells. Endocrinology (In Press).

Zaiko M, Estreicher A, Ritz-Laser B, Herrera P, Favor J, Meda P \& Philippe J 2004 Pax2 mutant mice display increased number and size of islets of Langerhans but no change in insulin and glucagon content. European Journal of Endocrinology 150 389-395.

Zeng X, Tamai K, Doble B, Li S, Huang H, Habas R, Okamura H, Woodgett J \& He X 2005 A dual-kinase mechanism for Wnt co-receptor phosphorylation and activation. Nature 438 873-877.

Zhu X, Zhou A, Dey A, Norrbom C, Carroll R, Zhang C, Laurent V, Lindberg I, Ugleholdt R, Holst JJ \& Steiner DF 2002 Disruption of PC1/3 expression in mice causes dwarfism and multiple neuroendocrine peptide processing defects. PNAS 99 10293-10298.

\section{Received in final form 20 March 2008 \\ Accepted 3 April 2008 \\ Made available online as an Accepted Preprint 3 April 2008}

